\title{
REFERENCES
}

1. J. Auslander, On the proximal relation in topological dynamics, Proc. Amer. Math. Soc. 11 (1960), 890-895.

2. R. Ellis, $A$ semigroup associated with a transformation group, Trans. Amer. Math. Soc. 94 (1960), 272-281.

3. R. Ellis and W. Gottschalk, Homomorphisms of transformation groups, ibid., 94 (1960), 258-271.

4. J. P. Clay, Proximity relations in transformation groups, Trans. Amer. Math. Soc. 108 (1963), 88-96.

STANFORD UNIVERSITY

\section{A TOTALLY BOUNDED, COMPLETE UNIFORM SPACE IS COMPACT}

\author{
D. L. FRANK
}

Let $X$ be a set and $U$ a uniformity on $X$. We will show that if $(X, U)$ is totally bounded, every net in $X$ has a Cauchy subnet. For each $d \in U$, let $S_{d}^{1}, \cdots, S_{d}^{n}$ be a finite covering of $X$ by $d$-spheres. Let $T_{d}$ be the topology on $X$ having $S_{d}^{1}, \cdots, S_{d}^{n}$ as its subbasis. Clearly the space $\left(X, T_{d}\right)$ is compact. Therefore, $Y=\prod_{d \in U}\left(X, T_{d}\right)$ is compact.

Now, let $\left(p_{i}\right)$ be a net in $X$. Then $\Delta \circ\left(p_{i}\right)$ is a net in $Y$, where $\Delta: X \rightarrow Y$ is the diagonal. By compactness, there exists a convergent subnet, $\left(q_{j}\right)$, of $\Delta \circ\left(p_{i}\right)$. Then $\Delta^{-1} \circ\left(q_{j}\right)$ is a subnet of $\left(p_{i}\right)$ which is clearly Cauchy.

Thus, if $(X, U)$ is also complete, every net in $X$ has a convergent subnet, so $(X, U)$ is compact.

Columbia University

Received by the editors March 12, 1964. 